\title{
Del bildungsroman a los estudios de juventud, un análisis de La tía Julia y el escribidor de Mario Vargas Llosa
}

\author{
From bildungsroman to youth studies, an analysis of Aunt \\ Julia and the scriptwriter, write by Mario Vargas Llosa
}

\author{
Edison Lasso Rocha \\ Universidad Andina Simón Bolívar, Quito, Ecuador \\ Contacto: edison.lasso@uasb.edu.ec \\ https://orcid.org/0000-0002-5075-5853
}

\section{Resumen}

En la literatura no son pocos los ejemplos que existen de novelas en las que el personaje central recorre su mundo, desde su juventud hasta su vida adulta, en busca de la experiencia que consolide su identidad. Tan es así que existe una categoría particular para entender este tipo de obras, conocidas como bildungsroman; sin embargo, es importante llevar el análisis a un nuevo nivel, a partir de plantear categorías propias de las ciencias sociales y concretamente de los estudios de juventud, para entender de mejor manera ese trayecto de búsqueda y realización que emprenden los jóvenes para insertarse socialmente. En este artículo se ha seleccionado la novela de Mario Vargas Llosa, La tía Julia y el escribidor, para mostrar las tensiones entre juventud y adultez.

Palabras claves: Bildungsroman; Juventud; Experiencia; Estudios culturales; Adultez; Mario Vargas Llosa

\begin{abstract}
In literature, there aren't a few examples of novels where the main character travels his or her world, from a young age to an adult life, searching for the experience that consolidates their identity, so much so that, there is a particular literary genre to understand this type of work, named Bildungsroman. However, it is critical to take this analysis to a new level, proposing other categories from a social science perspective and specifically youth studies in order to help understand the journey young people go through to find their identity and insert themselves in society. This article discusses the novel Aunt Julia and the scriptwriter, written by Mario Vargas
\end{abstract}

Keywords: Bildungsroman; Youth; Experience; Cultural studies; Adult age; Mario Vargas Llosa

Recibido: 20.07 .19

Aceptado: 02.10.19 


\section{Noción de juventud}

Para el año 1787, Jacques Louis David, uno de los pintores franceses más importantes de su tiempo, había recibido un sinnúmero de reconocimientos que lo situaban como uno de los artistas más importantes de su época; sin embargo, no había pintado aún los cuadros que, dentro de su obra, mayor trascendencia han tenido, precisamente por tener una vinculación histórico-política y por mostrar, quizá mejor que nadie, la figura de Napoleón Bonaparte, por medio de cualquiera de las cinco versiones que hiciera del emperador, todas ellas por encargo, montado sobre un caballo, a veces blanco, a veces castaño, en el paso de San Fernando, en los Alpes, rumbo a la batalla de Marengo, de la que saldría victorioso el ejército francés sobre las tropas austriacas; pero es en este mismo año de 1787, cuando el pintor contaba con treinta y nueve años de edad, que expuso uno de sus cuadros más singulares, se trata de La muerte de Sócrates.

En este cuadro se puede observar la representación de los últimos minutos de vida del filósofo griego, quien fuera condenado a morir por medio del suicidio; la escena es tensa, en ella podemos ver que destaca la figura de Sócrates, casi desnudo, sobre un catre situado dentro de un calabozo gris, iluminado ese instante por los últimos rayos de sol que entran desde una ventana inaccesible situada fuera del encuadre; en el centro está la copa de cicuta que un esclavo extiende con pesar hacia el filósofo, mientras él alarga su brazo derecho para tomarla, en tanto levanta su mano izquierda con el índice extendido en clara señal de oratoria, mientras un grupo de discípulos situados a la derecha y a espaldas de su maestro se lamenta hasta casi llegar al llanto por lo sucedido, por lo que está por acontecer; del otro lado, hacia el fondo, y en un plano secundario, se ve a la mujer de Sócrates, Jantipa, salir serenamente de la cárcel, precedida por dos criados de Critón, uno de los acompañantes del filósofo, y dentro del encuadre de la escena principal, al pie de la cama de su maestro se encuentra Platón, en actitud meditativa, sus ojos están cerrados y un fragmento de túnica cubre su boca, quizá para no interrumpir a su maestro.

Aunque este lienzo tiene varios errores de correspondencia con los sucesos históricos como se narran en el Fedón, el que más llama la atención, 
sin duda, es el que corresponde a la representación de Platón, y es que mientras los otros errores corresponderían a aspectos que quizá se le escaparon al pintor, este en cambio parece bien pensando y propositivo, pues no de otra forma pude entenderse la intención de David de incluir a Platón (dentro una escena en la que él jamás estuvo presente) pero no como realmente hubiera estado, es decir como un joven discípulo, sino como un anciano de manos arrugadas y cabeza calva, con pocos cabellos blancos, pues Sócrates murió en el año 399 a. C., cuando Platón tenía veintiocho años de edad.

Ahora bien, pensando con más detalle esta representación, quizá el mayor error habría sido incluir al alumno como realmente era, mas ¿cómo justificar entonces el peso del conocimiento, del prestigio, de la trascendencia, de la historia? David sabía, o intuía al menos, esto que Umberto Eco (2013) señala hoy en día: "Hay poderes inmateriales, que no se pueden evaluar a peso, pero que de alguna manera pesan" (p. 9) y mucho, hay que añadir; por ello es que la figura de Platón, dentro del cuadro, corresponde a una lógica construida socialmente y aceptada como una verdad absoluta: la juventud es una etapa dentro de la vida, y como tal posee algunos rasgos como la vitalidad, la inmadurez, la inexperiencia, la alegría, entre otros, opuestos a los que serían propios de la vejez: el cansancio, el conocimiento, la experiencia, la tristeza, por mencionar algunos.

El siguiente trabajo pretende analizar cómo funciona este mecanismo por el cual la juventud es vista como una categoría donde concurren diferentes tipos de tensiones. Para ello se tomará como objeto de análisis la obra La tía Julia y el escribidor de Mario Vargas Llosa.

\section{Contexto de la novela}

Antes de empezar el análisis relativo a la representación de juventud dentro de la novela, es importante conocer algunas de sus características contextuales, pues las mismas permitirán entender, de mejor manera, el sujeto de la enunciación que se configura en este escrito, sobre todo si se considera que:

Sea cual fuere la filosofía que genera una obra de arte, y aceptado, porque la historia del arte lo prueba y comprueba, que todas ellas, 
puestas en el plano del arte, son generadoras, debe reconocerse que también la historia de la cultura muestra algo: que las obras que sobreviven más tenazmente al olaje del tiempo son aquellas en las cuales se nos devela la naturaleza humana en una determinada circunstancia histórica que es, por lo mismo, circunstancia de una realidad concreta que 'manifiesta' al hombre. (Rama, 1986, p. 81)

Y para este caso concreto, la circunstancia que se busca entender es la juventud. Pero dado que esta es una categoría cuyo entendimiento depende de otros elementos, de un conjunto de condiciones epistémicas en las que el autor ha producido su obra, es importante conocer el contexto material de la misma y mirarlo no como un grupo de aspectos anecdóticos relativos a la novela, sino como unidades detonadoras de su producción.

En esta medida, se sabe que La tía Julia y el escribidor es la quinta novela escrita por Mario Vargas Llosa, y como señala Armas (2002): "es la más flaubertiana de las novelas de MVLL" (p. 315) precisamente por integrar dentro de su corpus la estructura de los radioteatros, tan populares en las décadas del cuarenta y cincuenta del siglo XX, y por desarrollar además una trama aparentemente plana, donde el amor debe superar una serie de dificultades, tal si fuera una historia estereotipada. Sin embargo, el mérito del autor es enorme, pues desarrolla una estructura donde consigue dar la vuelta a esta apariencia, logrando una obra con múltiples aristas, todas ellas pulidas con precisión.

Este texto del Nobel peruano fue escrito en el año 1977 y la trama está ambientada en la ciudad de Lima, justo al iniciar la segunda mitad del siglo XX, entre los años 1953 y 1954 para ser más exactos, y propone dos historias que se desarrollan paralelamente; he aquí una primera cara de este prisma, pues por un lado cuenta el surgimiento y posterior consolidación de la relación amorosa que se entabla entre el joven protagonista de la obra, Varguitas, quien tiene apenas dieciocho años de edad, con una mujer conocida como tía Julia, a quien la familia del joven rechaza no solo por la relación filial política que existiría entre ellos, sino sobre todo por ser ella divorciada y además catorce años mayor, es decir dotada de una experiencia censurada por la sociedad de entonces. 
Por otro lado, la segunda historia que se narra es la obsesión del protagonista por convertirse en escritor. En este proceso deberá enfrentarse a sus propias convicciones y madurar la idea de lo que significa ser escritor y hacer literatura, para distanciarse de lo que sería un escribidor y producir obras de consumo popular, tremendamente exitosas, pero al mismo tiempo en extremo evanescentes.

Vale la pena detenerse en este punto, ya que es aquí donde el autor incorpora un elemento que dota de una nueva significación a su propuesta, pues la voz narrativa que desarrolla la trama se muestra en primera persona; así, en lugar de presentarse a sí misma con un nombre cualquiera (lo cual habría sido sencillo hacerlo, como lo han hecho otros autores como Kerouac en su novela En el camino o Joyce en Retrato del artista adolescente, por ejemplo), decide identificarse como Mario Vargas. Ello sin duda puede prestarse a confusión y llevar a que un lector despistado asuma este libro como una historia personal, como un libro autobiográfico, pues al escribir la novela el objetivo que el autor se propuso fue:

To write a novel with stereotypes, with clichés, with all the instruments of the popular novel, the soap opera, and the radio serial, but in such a way that these elements could be transformed into an artistic work, into something personal and original. As in all my books, the idea came to me from a personal experience. (Vargas Llosa, 1991, p. 107)

Además, su objetivo al escribir esta ficción era llegar a un sitio poco explorado. Cuenta el autor, dentro de este mismo libro de donde procede la cita anterior, publicado, por cierto, únicamente en idioma inglés, y en donde reflexiona acerca de su oficio como escritor, su interés por experimentar con esta novela y alternar las ficciones del escribidor con su propia historia, usando no solamente su nombre, sino su propia experiencia de vida hasta esa época.

Cosa que seguramente contribuyó a una lectura sesgada del libro, pues cuando se publicó esta obra, el autor, que ya era un escritor reconocido y había ganado varios premios, el más importante el Rómulo Gallegos por su segundo libro La casa verde, con toda seguridad conocía la lógica del campo literario y 
ofreció al público una nueva novela de la misma manera que lo haría cualquier autor, es decir el solo texto esperando que el libro se defienda por sí solo.

No obstante, quizá esto no ocurrió del todo, pues la recepción de la novela provocó muchos paratextos, como las reacciones de Julia Urquidi, la tía Julia, quien publicó su propia versión de lo ocurrido, titulada Lo que Varguitas no dijo (Urquidi Illanes, 1983), favoreciendo a crear una suerte de crónica rosa alrededor de esta obra, de allí que el adjetivo de flaubertiana no sea arbitrario. Por este motivo, veintidós años después de la primera edición, y siete posteriores al libro contestatario de la tía Julia, Vargas Llosa decide incorporar un prólogo a este libro para aclarar: "el género novelesco no ha nacido para contar verdades, que estas, al pasar a la ficción, se vuelven siempre mentiras (es decir, unas mentiras dudosas e inverificables)" (Vargas Llosa, 2012, p. 9), lo que permite orientar definitivamente la lectura, y asumir esta historia como un mundo ficcional, configurando así, otra cara del prisma, pues en el fondo este mundo ficcional propone una discusión acerca de cuáles serían los límites que separan a la ficción de la realidad.

Otro aspecto que es importante señalar, arista en realidad desde donde el prisma se hace más complejo, tiene que ver con la arquitectura narrativa de la obra. Al respecto no es suficiente decir que la estructura de la novela y el sentido de la historia se construye a saltos, debido a que los capítulos impares narran los sucesos en la vida de Varguitas, es decir todo lo que tiene que ver con las dos lecturas mencionadas anteriormente ${ }^{1}$; mientras que los capítulos pares exponen ejemplos de radioteatros creados por Camacho, sino que la propuesta original de la voz narrativa va mucho más allá, pues su intención es exponer:

[...] los distintos sucesos, articulados en un sistema de vasos comunicantes, [que] intercambian vivencias y se establece entre ellos una interacción gracias a la cual los episodios se funden en una unidad que hace de ellos algo distinto de meras anécdotas yuxtapuestas. Hay vasos comunicantes cuando la unidad es algo más que la suma de las partes integradas en ese episodio. (Vargas, 1997, p. 87)

Es importante destacar este aspecto debido a que gracias a él podemos asistir a esta lucha entre el escritor y el escribidor, a través de un género particular de la literatura que se conoce como el bildungsroman, o novela de formación. Se puede 
decir que esta es un tipo de novela que da cuenta de la evolución o transformación de un personaje central, desde un momento de su vida marcado por la necesidad de aprender algo fundamental, mediante un proceso que inicia en su juventud y culmina en el momento en que ha alcanzado la experiencia que requiere, generalmente en la edad adulta. Sin embargo nótese que al hablar de este tipo de novela no se especifica qué es lo que debe aprender pues "es esta precisamente la perspectiva del bildungsroman: una novela que centra su atención en el proceso de formación del protagonista" (Bohórquez, 2006, p. 190); de esta manera, tendrá especial relevancia las circunstancias de su aprendizaje, debido a que ellas influirán en la forma de construir el mundo por parte del héroe del relato.

Se aclara esto último por la siguiente razón: otro de los aspectos peculiares de esta obra de Vargas Llosa, y, por tanto, una nueva superficie del prisma, es que la novela tiene un pie firmemente situado en el bildungsroman; sin embargo, debido a su temática y a la reflexión que se propone alrededor del campo artístico desde la mirada que ofrece la literatura, hay que destacar que el otro pie de la novela lo tiene puesto en un giro del bildungsroman "centrado en el desarrollo de un artista y tematiza un crecimiento particular y personal" (Álamo, 2011, p. 30). Se trata entonces de una variación de la novela de formación llamada kunstleroman.

Aunque en muchos casos las taxonomías no resulten sino ejercicios arbitrarios, cuya intención es distanciarse de las formas canónicas de entender un objeto de estudio, y la literatura no está ausente de ello, la diferenciación entre bildungsroman y kunstleroman es importante dado que en la novela de Vargas Llosa se evidencia el distanciamiento que existe entre escritor y escribidor, lo cual lejos está de ser una diferenciación semántica solamente, pues en primer lugar la mutación morfológica de la palabra escritor, para formar escribidor hoy en día puede pasar inadvertida debido a que el término ha sido aceptado por la Real Academia Española para hacer referencia irónicamente a un escritor, pero se debe considerar que hace treinta y ocho años, cuando se publicó la novela, no era así; en esta medida incluso puede aceptarse que Vargas Llosa acunó el término.

En segundo lugar, la manera en que se presentan ambos signos devela 
que la intención es justamente oponerlos dentro del propio campo de la literatura, situando por una parte a quien espera valerse de la escritura, usando principios tempranos del marketing y la publicidad, así como una suerte de producción fordista para la producción de textos de entretenimiento masivo y, por otra parte, de quien aspira dedicarse al arte, según un mecanismo externo de ordenación del discurso, y se dice externo por cuanto debemos considerar que Varguitas es un proyecto de escritor aún, por lo tanto alguien quien mira desde fuera el mundo de la literatura; en esa medida todavía no distingue plenamente sus límites y posibilidades, lo que lo mantiene expectante y deseoso de acceder a él.

Foucault dio cuenta de esto a través de lo que él llamó "Tabú del objeto", un privilegio que solo ostentan unos cuantos para hablar y opinar de lo que más conocen; es decir, un proceso de exclusión por el que "uno sabe que no tiene derecho a decirlo todo, que no se puede hablar de todo en cualquier circunstancia, que cualquiera, en fin, no puede hablar de cualquier cosa” (2005, p. 14). Ello ayuda a entender el carácter cuasi sagrado de determinadas disciplinas y las dificultades que existen para acceder a ellas, lo cual tiene que ver también con un punto clave desarrollado por el propio Vargas Llosa, quien afirma:

It is not true that the difference between a soap-opera writer and an artistic writer is that a soap-writer writes for money and an artistic writer write only for glory. No. Many artistic writers also write for money, and writers of soap-operas sometimes write for glory and artistic achievement. I think the difference is the difference that Roland Barthes made between écrivante and écrivain (escribiente y escritor). If I remember, he said an écrivante is someone who uses language only as an instrument, an instrument through which a message, any sort of message, can be transmitted. And écrivain, a writer, is someone who uses language as an end in itself, as something that in itself has justification. (Vargas, 1991, p. 115)

Ahora bien, esta distinción entre escribidor y escritor que señala el autor es la que se plasma con más fuerza en la novela. Así, el uso que hace del lenguaje Pedro Camacho es meramente instrumental, y transita entre las funciones conativa y fáctica del lenguaje, la primera en la medida en que pone énfasis en el oyente, en la audiencia, y mediante la construcción de los relatos busca crear un vínculo 
de fidelidad que depende tan solo de quien escucha, por tanto pretende, como cualquier medio de comunicación masivo, donde se producen dichas historias, acceder a la segunda función y mantener el canal de comunicación abierto, independientemente de las intenciones de su productor, ya que las mismas se hayan supeditadas a las intenciones materiales del medio.

Mientras que la voz narrativa de Varguitas declara no solo su interés, sino su necesidad de hacer un uso del lenguaje desde la función poética, es decir, desde el propio ejercicio de la literatura, y señala en este pasaje algo que es posible encontrar como síntesis en al menos cinco de ellos a lo largo de la novela: "Cada vez me resultaba más evidente que lo único que quería ser en la vida era escritor y cada vez, también, me convencía más que la única manera de serlo era entregándose a la literatura en cuerpo y alma" (Vargas Llosa, 2012, p. 269), pues es en ella en donde el protagonista encuentra justificación a su existencia. Es su razón de ser.

La idea anterior nos remite nuevamente a Foucault, quien sostiene que en la escritura se consolidaría la conciencia de uno mismo, a través de una "escritura de sí" que permite pensarse y construir una identidad a partir de este ejercicio:

El papel de la escritura es constituir, con todo lo que la lectura ha constituido, un "cuerpo" (quicquid lectione collectum est, stilus redigat in corpus). Y dicho cuerpo ha de comprenderse no como un cuerpo de doctrina, sino - de acuerdo con la metáfora tan frecuentemente evocada de la digestión - como el propio cuerpo de quien, al transcribir sus lecturas, se las apropia y hace suya su verdad: la escritura transforma la cosa vista u oída "en fuerzas y en sangre" (in vires in sanguinem). Viene a ser en el propio escritor un principio de acción racional. (1999, p. 296)

Por tanto, se hace difícil, sino imposible, separar entre el ser y la escritura. Más aún en una novela como esta, en donde existe la ilusión de estar leyendo no una invención, sino una historia verdadera, llena de matices, reflexiones, sucesos y aprendizajes que van a modelar la experiencia y la forma de entender el mundo del personaje central. Así, hay que recordar que este también es el terreno de la novela de formación, sobre la cual resta señalar un aspecto. 
En el bildungsroman, el héroe "está poseído por el demonio de sus propios estímulos interiores, que le empujan a la consecución de sus fines, a la búsqueda de la plenitud" (Rodríguez, 1996, p. 43), de la experiencia, del desprendimiento ansioso de los rasgos que, como un estigma, marcan al personaje y lo sitúan en un lugar incómodo del que se quiere salir. Esto le ocurre a Varguitas en la novela, quien no solamente muestra su obsesión con llegar a ser un escritor reconocido, sino con dejar de lado los rasgos que lo identifican con un jovencito sin experiencia.

Desde esta perspectiva, el bildungsroman ofrece la posibilidad de entender, por una parte, esta necesidad de la voz narrativa por devenir en escritor, mientras que es en el campo de los estudios de juventud, relativamente recientes en los estudios culturales, donde se puede entender de mejor forma esta lucha por la que atraviesa el personaje central de la novela.

\section{Del bildungsroman a los estudios de juventud}

Al hablar de los estudios de juventud es importante empezar diciendo que el objeto de estudio hoy en día supera los criterios tradicionales de análisis, que reducían el entendimiento de lo que significa la juventud a dos puntos de vista bastante limitados, aunque inicialmente con una intención objetiva. Estos son, por un lado la biología, cuya correspondiente categoría vinculada con la juventud se llama pubertad, y permite dar cuenta de los cambios físicos que ocurren en el cuerpo a partir de una edad específica; y, por otro, la psicología, que erige el criterio de adolescencia para entender los cambios mentales que pueden ocurrir en los jóvenes. No obstante, estas dos visiones a partir de las cuales se ha entendido a la juventud, como una etapa de transición entre la niñez y la adultez, una etapa que debe cumplirse irremediablemente y que otorga unos rasgos particulares al ser humano, generalmente tensos y sufridos por todos los cambios que significan en diferentes niveles, poco aportan para entender por ejemplo ritos, símbolos, gustos, necesidades y otros elementos igual de importantes que los biológicos o psicológicos, que posibilitan hoy en día hablar no solo de lo que significa estar joven, sino también ser joven. 
Desde este punto de vista, que es el de los estudios culturales, “la juventud es un 'estado', no una etapa de transición, ni un proceso de metamorfosis" (Reguillo, 2003, p. 106); es decir, se trata no de una fase, sino de una forma de vivir, una manera de comportarse, de asumir las relaciones sociales y desenvolverse en las diferentes circunstancias de la vida con un conjunto de códigos establecidos, algunos de ellos considerados también estereotípicos, y que en la sociedad actual permiten identificar a los sujetos, interpelándolos, desde el punto de vista de Althusser, como jóvenes habitando en una sociedad.

La ventaja que ofrecen los estudios culturales para entender la juventud radica en la apertura que existiría hacia las formas de ser joven, y sobre todo la importancia de eludir clasificaciones rígidas, pues la juventud no se trata, como se ha dicho, de un periodo dentro de la vida, ni un espacio homogéneo donde unos sean iguales a otros.

Al inscribir la juventud dentro de lo social, por tanto, la primera premisa que surge es que esta no es una categoría que aparezca de la misma manera siempre; existen jóvenes y jóvenes, cada cual con sus preocupaciones, con sus necesidades y sus intereses, no es lo mismo ser joven en la ciudad de Lima en el año 2015, que ser joven en Lima en 1953. Sentirse joven es una cosa, reconocerse como tal y al mismo tiempo rechazar esa condición debido a la urgencia por resolverse identitariamente como un escritor es otra, y querer ser un hombre objeto de derechos es también otra condición, que al combinarse todas juntas dan como resultado las características del personaje Varguitas.

Un primer aspecto que se puede tener en cuenta desde esta perspectiva es que la oposición entre escritor y escribidor, analizada antes a partir del bildungsroman, ofrece una serie de subcategorías que permiten situar a uno y a otro como antagonistas. Ello demuestra que al hacer el rastreo dentro de la novela de los lugares en donde se encuentra representada tanto la juventud - vinculada con el aspirante a escritor—, como la madurez — relacionada con el escribidor-, los términos que se pueden inferir en cada caso son muchos.

Así, de manera concreta las expresiones que se deducen de los pasajes Letras-Lima 90(132), 2019 
referentes a la juventud son: sensualidad, vitalidad, jovialidad, alegría, energía, seguridad basada en el cuerpo, dependencia, actitud, inexperiencia, inseguridad, inmadurez, entre otras. De esto, como puede notarse, existe un tránsito entre lo positivo y lo negativo, demostrando en este sentido la presencia de dos cualidades de la juventud presentes como un rasgo paradójico. Ello quiere decir que al mismo tiempo que la juventud sería un "estado" ideal al que cualquier persona quisiera acercarse, también sería un período de rechazo, dado que impediría la realización de una persona como sujeto de plenos derechos.

A diferencia de los anteriores, los aspectos referidos a la madurez encontrados en diferentes pasajes son los siguientes: vicios, experiencia, sexualidad, carga, estigma, vejez, vergüenza, rechazo, apogeo cerebral, merecimiento de respeto, merecimiento de admiración, miedo a la muerte, sabiduría, mayor capital económico, entre otros. Todo ello demuestra una tensión entre la juventud y la madurez; así, la pugna es evidente cuando, por ejemplo, se confronta sexualidad con inocencia, experiencia con inexperiencia, sabiduría con inmadurez, apogeo cerebral con locura o el que tiene que ver con el capital económico, un aspecto importante que está presente en varios instantes de la novela, y tiene la capacidad de conceder independencia y respetabilidad a quien lo posee, así como otorgar limitaciones a quien carece de él. Esto se puede ver en el siguiente pasaje, en el que la voz narrativa cuenta que fue a casa de su tío con la intención de encontrar a la tía Julia, pero sin éxito:

Sin embargo, al llegar a la casa de Armendáriz ese mediodía, para el almuerzo acostumbrado, me encontré con que no estaba. La tía Olga me contó que la había invitado a almorzar "un buen partido": el doctor Guillermo Osores. Era un médico vagamente relacionado con la familia, un cincuentón muy presentable, con algo de fortuna, enviudado no hacía mucho.

—Un buen partido — repitió la tía Olga, guiñándome el ojo- Serio, rico, buen mozo, y con sólo dos hijos que ya son mayorcitos. ¿No es el marido que necesita mi hermana? (Vargas, 2012, p. 214)

Este fragmento muestra, además de la importancia del aspecto económico, la forma en que se concibe la madurez, tácitamente opuesta a la juventud de 
quien narra el episodio, y quien líneas más adelante demostrará sus celos hacia este personaje de relieve, un hombre maduro, centrado, respetable, atractivo, en fin, alguien que reúne las condiciones idóneas (y en las que la voz narrativa no se reconoce) para entablar una relación formal y que aparece solo una vez en la historia para señalar el grado que va adquiriendo la relación entre Marito y la tía Julia. La unión entre estos personajes permite observar un aspecto interesante de la representación de juventud, y la misma tiene relación con esta idea de rechazo que dentro de la novela provoca la condición de ser joven por dos razones.

La primera se deriva de la diferencia de edad entre Varguitas y Julia. Aunque esto pueda parecer un argumento ligado a lo biológico, no lo es del todo, pues es una construcción social la que establece el impedimento de mantener o consumar relaciones amorosas entre personas con marcadas diferencias de edad, no solo por el aspecto etario sino sobre todo por las implicaciones de madurez biológica, psicológica y emocional que son deseables en ambos miembros de la pareja a efectos de procurar vínculos fuertes, que resistan los avatares de la vida diaria.

Por este motivo, Varguitas no solo rechaza la forma en que Julia lo interpela, es decir como "Marito", pues las connotaciones infantiles y de inmadurez son evidentes en el diminutivo del nombre, sino que se presenta a sí mismo no como un joven, sino como un hombre autosuficiente, respetable, digno de admiración, para lo cual se valdrá de su ejercicio literario a fin de mostrar cualidades de una persona analítica de la sociedad, pero sobre todo como un hombre con experiencias vastas de todo tipo, que le permiten ponerse al mismo nivel de la mujer que pretende conquistar: "- Soy un hombre hecho y derecho -le aseguré, cogiéndole la mano, besándosela- Tengo dieciocho años. Y ya hace cinco que perdí la virginidad" (Vargas, 2012, p. 26). Esto demuestra la clara intención del personaje por construirse a sí mismo como sujeto adulto, capaz de responder como tal en todos los niveles que correspondan, aunque ello implique de alguna manera mimetizarse para adquirir rasgos de madurez — por ejemplo, dejarse el bigote a efectos de parecer mayor edad y librarse del peso que significa la juventud y la inexperiencia-. 
Aunque este último aspecto parezca insignificante, tiene también su justificación desde el orden de lo legal: las leyes sancionan este tipo de relaciones consideradas como perversas debido a que existiría una manifestación contra natura en ello, aspecto que los propios protagonistas conocen, tal como se expone en el siguiente fragmento en el que Julia empieza a dimensionar los alcances que pueden llegar a tener sus amoríos:

- He estado pensando mucho y la cosa ya no me gusta, Varguitas. ¿No te das cuenta que es absurdo? Tengo treinta y dos años, soy divorciada, ¿quieres decirme qué hago con un mocoso de dieciocho? Esas son perversiones de las cincuentonas, yo todavía no estoy para esas. (Vargas Llosa, 2012, p. 223)

Por este motivo es que los protagonistas deberán buscar mecanismos que les permitan eludir las sanciones sociales y familiares que se avecinan, pues Varguitas, al tener tan solo dieciocho años, para la sociedad peruana se trata de una persona que aún no ha alcanzado la mayoría de edad; por tanto, es un jovencito que no podría tomar sus propias decisiones debido a que la tutela de sus padres estaría sobre su forma de proceder.

Finalmente, la segunda razón por la que la condición de ser joven es rechazada en Varguitas tiene que ver con el capital simbólico que persigue, su necesidad de convertirse en escritor, su temor al final de devenir en escribidor. Varguitas está obsesionado con ser escritor, esto ya se lo dijo en su momento; no obstante, sabe que para escribir el único medio de lograrlo es escribiendo, de allí que el epígrafe de la novela que recoge un texto de Salvador Elizondo sea absolutamente pertinente: "Mentalmente me veo escribir que escribo...", dice una de sus líneas. Es decir, dedicarse a la literatura sin mayores distracciones a fin de construirse un nombre, de ganar poco a poco la experiencia, que para Benjamin es una especie de accesorio común que se ofrece de la misma manera a todos los sujetos, razón por la cual esta "máscara del adulto [...] inexpresiva, impenetrable, siempre igual" (Benjamin, 1989, p. 41), sería un componente esencial de la modernidad, pues por un lado iguala a los sujetos en su condición de seres productivos, adultos en definitiva, y por otro les compensa con su realización identitaria; este es el reconocimiento de escritor que tanto ansía Varguitas para 
proyectar una imagen que corresponda a lo que su obra significa, de modo que si alguna vez surge la oportunidad de ser representado, como lo hizo David con Platón en el cuadro de Sócrates comentado al inicio, la imagen que se muestre no importe si es la de un hombre viejo y sabio o la de un joven prometedor, sino la de alguien que trabajó la palabra incansablemente.

\section{Notas}

1 Por un lado la referida a la relación amorosa con la tía Julia, y, por otro, la que muestra su fuerte atracción y posterior desencanto hacia la figura de Pedro Camacho, el escribidor, cuyos radioteatros se presentan desde una suerte de realismo amarillista, impactantes al inicio, a diferencia de los que constan al final, que son repetitivos, tal como se constituye la producción de este tipo de subgénero narrativo.

\section{Referencias bibliográficas}

Álamo, F. (2011). Los subgéneros novelescos (Teoría y modalidades narrativas). Almería: Editorial Universidad de Almería.

Armas, M. (2002). Vargas Llosa. El vicio de escribir. Barcelona: Alfaguara.

Benjamin, Walter. (1989). Escritos. La literatura infantil, los niños y los jóvenes. Buenos Aires: Ediciones Nueva Visión.

Bohórquez, D. (2006). Novela de formación y formación de la novela en los inicios del siglo XX. En C. Pacheco y L. Barrera (Coor.), Nación y literatura. Itinerarios de la palabra escrita en la cultura venezolana ( $\mathrm{pp}$. 189-200). Caracas: Fundación Bigott, Banesco, Editorial Equinoccio.

Eco, U. (2013). Sobre literatura. Barcelona: Debolsillo.

Foucault, M. (1999). Estética, ética y hermenéutica. Barcelona: Paidós.

Foucault, M. (2005). El orden del discurso. Barcelona: Tusquets.

Rama, Á. (1986) La novela en América Latina. Panoramas 1920-1980. Montevideo, Xalapa: Fundación Ángel Rama, Universidad Veracruzana.

Reguillo, R. (2003). Las culturas juveniles: un campo de estudio; breve agenda para la discusión. Revista Brasilera de Educación, 23, 103-118. Recuperado de http://www.scielo.br/pdf/rbedu/n23/n23a07.pdf

Rodríguez, M. de los Á. (1996). La novela de autoformación. Una aproximación teórica e histórica al bildungsroman desde la narrativa hispánica. Alemania: Edition Reichenberger. 
Edison Lasso Rocha

Urquidi Illanes, J. (1983). Lo que Varguitas no dijo. La Paz: Editorial Khana Cruz.

Vargas Llosa, M. (1991). A writer's reality. Siracusa: Syracuse University Press.

Vargas Llosa, M. (1997). Cartas a un joven novelista. Madrid: Planeta.

Vargas Llosa, M. (2012) La tía Julia y el escribidor. Madrid. Punto de Lectura. 